\title{
Documentar a si mesmo: resistência nas sociedades de controle
}

\section{Documenting oneself: resistance in the societies of control}

Resumo:

Para tentarmos uma definição de documentário é preciso levar em conta, no mínimo, três vertentes do problema: a história do documentário; sua estilística e sua dimensão ética. O que quer dizer, hoje, um documentário sobre um eu que faz asserções sobre si mesmo? Podemos pensá-lo como uma forma de reafirmar a existência, como uma tentativa de linha de fuga nas sociedades de controle? De afirmação da vida que não cessa de ser capturada pelos aparatos do capitalismo? Se assim for, a potencialidade política desse tipo de produção seria de resistência como re-existência, como insistência em existir. Este artigo, teórico, a partir do contexto da biopolítica e das sociedades de controle, tem como objetivo argumentar filosoficamente a favor da produção videográfica caseira e pessoal, compartilhada na Rede, como forma de resistência hoje.

Palavras-chave: Documentário pessoal. Biopolítica. Sociedades de controle. Resistência.

\section{Abstract:}

In order to try to come to a definition of documentary, it is necessary to take at least three aspects of the problem into consideration: the history of the documentary, its stylistics and its ethical dimension. What does a documentary about an I who makes assertions about him/herself mean today? May we think of it as a way to affirm existence, as an attempt to exercise a line of flight in the societies of control? As a way to affirm a life which never stops being captured by the apparatus of capitalism? If that is the case, the political potentiality of this kind of production would be resistance as re-existence, as an insistence on existing. This article, theoretical, based on the context of biopolitics and the societies of control, aims to argue philosophically in favor of individual home video production, shared in the net, as a way of resistance nowadays.

Key words: Personal documentary. Biopolitics. Societies of Control. Resistance.
ASPIS, Renata Lima. Documentar a Si Mesmo: resistência nas sociedades de controle. Informática na Educação: teoria \& prática, Porto Alegre, v. 13, n. 1, p. 67-74, jan./jun. 2010.

\section{Renata Lima Aspis}

Unicamp

Like the state, the camera is never neutral

(RENOV, M.)

\section{Documentário}

Talvez seja difícil investigar as fronteiras entre o documentário e o não-documentário em busca das características que o singularizam se não levarmos em conta, no mínimo, três vertentes do problema: a história do documentário, ou seja, sua evolução no tempo; sua estilística, ou seja, uma forma que o define nos diferentes tempos, suas características narrativas e finalmente sua dimensão ética, ou seja, o conjunto de valores que sustenta a produção documentária. Assim sendo, podemos dizer que há um discurso ideológico que sustenta uma determinada estilística que se modifica historicamente.

[...] documentário é uma narrativa com imagens-câmera que estabelece asserções sobre o mundo, na medida em que haja um espectador que receba essa narrativa como asserção sobre o mundo. A natureza das imagens-câmera e, principalmente, a dimensão da tomada através da qual as imagens são constituídas determinam a singularidade da narrativa documentária em meio a outros enunciados assertivos, escritos ou falados. [...] Ao contrário da ficção, o documentário estabelece asserções ou proposições sobre o mundo histórico. (RAMOS, 2008, p. 22) 
A partir disso podemos afirmar que o documentário tem algo a dizer, ele narra, há uma verdade que está em jogo, que precisa ser anunciada. Nesse sentido pensamos que o documentário é sempre político, pois diz algo sobre a realidade, é um juízo. "O documentário, portanto, se caracteriza como narrativa que possui vozes diversas que falam do mundo e de si." (RAMOS, 2008, p. 24).

Poderíamos perguntar: quem enuncia? Qual o lugar de onde quem enuncia fala? Quais os valores que sustentam essa fala? Assim nos voltamos para a questão da dimensão ética do documentário.

As diferentes éticas, que mudam através dos tempos, são históricas e isso significa dizer que as condições sócio-políticas de cada época, as econômicas, o desenvolvimento tecnológico (permitindo ou interditando determinadas idéias na produção documentária), as maneiras como os homens pensam a si mesmos e ao mundo, estão intrinsecamente relacionados com o modo do documentário em cada época. Esses aspectos da realidade são levados em consideração, a partir da década dos anos 90 do século $X X$, pelas correntes teóricas que pensam a produção do documentário. Tomemos como exemplo o documentário clássico inglês dos anos 30. Esta é uma produção fílmica financiada pelo Estado que enuncia as realizações desse Estado e é veiculada em lugares públicos como praças e escolas assim como em sindicatos. O documentário britânico nessa época tem a clara missão de educar as massas, sua ética educativa, portanto, está calcada na decisão de servir ao Estado, sequer encontramos créditos dos realizadores nos filmes, é uma produção abnegada, feita em nome do bem da nação. O filme Coal Face (Rosto de Carvão) de 1935, por exemplo, para um espectador desatento, é um filme sobre a produção de carvão na Inglaterra, apenas. No entanto, podemos, com mais atenção, perceber, pelo modo como se desenrola uma forte glorificação do trabalhador, colocado quase como um herói, aquele que se esforça e que dá a sua vida pelo progresso da pátria. Há um forte enaltecimento da capacidade industrial britânica, servindo como propaganda do Estado. Aqui podemos detectar não apenas uma intenção de propagar os feitos específicos do Estado naquele momento, mas também a ideologia que o sustenta, a democracia liberal, em contraposição aos perigos do emergente totalitarismo crescente na Europa na ocasião. Além disso, nessa época, estamos vivendo o deslumbramento dos homens diante das suas novas invenções tecnológicas de comunicação de massa e suas possibilidades de influência no pensamento das pessoas, o que chamamos formação de opinião pública.

A partir desse exemplo de ética educativa na narrativa documentária, da relação entre as asserções que determinada produção faz e seu entorno social, cremos que podemos entender que:

Chamamos de ética um conjunto de valores, coerentes entre si, que fornece a visão de mundo que sustenta a valoração da intervenção do sujeito nesse mundo. O corpo-a-corpo com o mundo - através da mediação da câmera, conforme se abre para o espectador e é por ele determinado - sempre foi uma questão premente para o documentário. A ética compõe o horizonte a partir do qual cineasta e espectador debatem-se e estabelecem sua interação, na experiência da imagem-câmera/som conforme constituída no corpo-a-corpo com o mundo, na circunstância da tomada. (RAMOS, 2008, p. 33)

Assim podemos nos aproximar de nossa questão sobre uma tendência da produção de documentários atual, o documentário em primeira pessoa: qual a ética que sustenta um documentário sobre um eu que faz asserções sobre si mesmo? E quais são as condições sociais, político-econômicas que permitem essa ética?

\section{Biopolítica: as condições sociais, político-econômicas que permitem essa ética}

\begin{abstract}
Mas, o que se poderia chamar de 'limiar de modernidade biológica' de uma sociedade se situa no momento em que a espécie entra como algo em jogo em suas próprias estratégias políticas. O homem, durante milênios, permaneceu o que era para Aristóteles: um animal vivo e, além disso, capaz de existência política; o homem moderno é um animal, em cuja política, sua vida de ser vivo está em questão. (FOUCAULT, 1980, p. 134)
\end{abstract}

Quando o filósofo francês Michel Foucault, morto em 1984, cria o conceito de biopolítica, está praticando a genealogia como método de investigação: procura, por meio da análise 
histórica, como o poder pode ser explicativo da produção de saberes. Esse poder não é exclusivo do Estado, não necessariamente é repressão e violência. É um poder que atua sobre os fenômenos naturais que se manifestam em determinado grupo, em determinada época. Trata-se de entender o poder mais como uma estratégia, não é só jurídico/institucional, não se restringe à classe dominante. Seria o poder que se constitui em mecanismos que produzem gestos, atitudes e saberes, que permeia toda a cultura, domina os corpos. A partir da Modernidade esses mecanismos são mecanismos de normalização, de disciplinarização dos corpos, confinados em instituições, submetidos às suas regras. O indivíduo não pára de recomeçar passando da família à escola, da escola à fábrica, ocasionalmente hospitalizado ou preso: confinamento. São as chamadas sociedades disciplinares. Disciplina que produz corpos dóceis, triunfo do capitalismo, corpos dóceis para a produção. Este é um poder que domina cada célula: a saúde passa a ser pública controlada através de campanhas de vacinação, distribuição de camisinha, pré-natal obrigatório; passa a haver políticas públicas de educação, exercendo-se o poder sobre o currículo de cada aluno, a obrigatoriedade da escolarização; também no campo do trabaIho esse poder disseminou-se, administrando, fazendo regras e controlando cada trabalhador, seu tempo de trabalho e de descanso, sua vida pós período ativo, etc. Estamos todos matriculados, temos nossos números de identificação na massa que se move segundo uma, como chama o filósofo, microfísica do poder, que atua diretamente na vida de cada um constituindo-se como um, ainda segundo Foucault, biopoder. É disso que se trata quando Foucault fala da inversão da idéia clássica de Aristóteles de que além de ser um ser vivo o homem é um animal político, que se humaniza na polis. Hoje a política humana é travada através dos corpos, da vida dos homens, o que ele chamou de biopolítica. Trata-se aqui do abandono da análise marxista das relações de poder que está pautada fundamentalmente na contradição entre classes sociais. Sob essa perspectiva o poder está reduzido às relações de produção nas relações de trabalho.

Gilles Deleuze, também filósofo francês, um pouco depois, em 1990, batiza a nova fase dessas sociedades disciplinares, das quais Foucault já tinha previsto o ocaso, a partir da
Segunda Guerra: sociedades de controle. Hoje o jogo na política e na economia - já inseparáveis -, não é mais de contradição. O biopoder disseminado por tudo nos faz desejar o controle como condição de existência. Não há adversário, luta de classes. Não há mais o pingue-pongue patrão-empregado. No capitalismo financeiro deslizamos entre empresas e serviços. Na empresa só há gerentes. O dinheiro é virtual: ações (DELEUZE, 1992b). Estamos todos igualmente presos à grande roda que roda por si.

O filósofo italiano contemporâneo Giorgio Agamben (AGAMBEN, 2004, p. 12) afirma que "[...] a política parece hoje atravessar um duradouro eclipse $[\ldots] "$ ". O que pode ser uma forma delicada de dizer que hoje já não existe política, não no sentido clássico. Hoje, o conceito antigo de política precisa ser repensado justamente no território da biopolítica, não podemos escapar disso. Concordando com Foucault ele afirma:

[...] o ingresso da zoé [simples fato de viver, comum a todos os seres] na esfera da pólis, a politização da vida nua como tal constitui o evento decisivo da modernidade, (...) assinala uma transformação radical das categorias políticofilosóficas do pensamento clássico. (AGAMBEN, 2004, p. 12)

O contemporâneo sociólogo e filósofo Maurizio Lazzarato, pesquisador dos movimentos pós-socialistas, ao fazer sua análise do capitalismo hoje vai afirmar o capitalismo não mais como um modo de produção, mas como produção de mundos. A fábrica produzia mercadorias, hoje a empresa produz mundos. 0 capitalismo, segundo o filósofo, nos apresenta um mundo único, sem saídas, negando aos homens a criação de mundos possíveis. A vida é constantemente capturada.

O corpo paradigmático da sociedade de controle não é mais o corpo aprisionado do trabalhador, do louco, do doente [referência às instituições de confinamento das sociedades disciplinares], mas o corpo obeso (cheio de mundos da empresa) ou anorético (recusa destes mesmos mundos) que observa pela televisão os corpos mortos pela fome, pela violência e pela sede da maior parte da população mundial. (LAZZARATO, 2006, p. 76)

Podemos dizer que há uma clara relação entre o desenvolvimento da microeletrônica e 
das sociedades de controle. Na sociedade de controle já não é mais necessário o confinamento para disciplinamento. O controle é feito a céu aberto, pois já temos aparato eletrônico suficiente que permite aos homens viverem como animais em uma reserva. De dentro pode-se ter a ilusão de que a vida está livre, selvagem, potente. Nem mesmo há a necessidade do chip amarradinho no tornozelo. O chip que nos monitora 24 horas por dia via satélite está embutido em nossos acessórios de trabalho e de lazer. Não é mais necessário o confinamento porque já é possível o controle contínuo e a comunicação instantânea. "Face às formas próximas de um controle incessante em meio aberto, é possível que os confinamentos mais duros nos pareçam pertencer a um passado delicioso e benevolente." (DELEUZE, 1992a, p. 216).

As sociedades de controle nas quais vivemos agora são baseadas na exposição, na transparência, todos devem se expressar o mais possível, para que se possa ver-lhes as entranhas, monitoradas a distância em um continuum infinitum. A exposição constante desde opiniões banais sobre toda e qualquer coisa, seguir todo e qualquer um no Tweeter, por exemplo, expor sentimentos e fatos nos sites de relacionamento são práticas comuns que fazem hoje o sentimento de estar vivo. Estar vivo é estar aparente, exibido. A exposição contínua vira moda, vira desejo e condição de existência, não é mais necessário vigiar e punir. Não é mais necessário o panóptico, a visibilidade constante é oferecida de bom grado, a vigilância é desejada. Vivemos em um movimento cada vez mais rápido de captura da vida, "[...] o homem da disciplina era um produtor descontínuo de energia, mas o homem do controle é antes ondulatório, funcionando em órbita, num feixe contínuo [...]" (DELEUZE, 1992b, p. 216), sempre on-line, sempre ligado, plugado, antenado.

\section{Resistência: a ética que sustenta um documentário sobre um eu que faz asserções sobre si mesmo}

Se na modernidade a resistência obedecia a uma matriz dialética, de oposição direta das forças em jogo, com a disputa pelo poder concebido como centro de comando, com os protagonistas polarizados numa exterioridade recíproca, mas complementar, o contexto pós-moderno suscita posicionamentos mais oblíquos, diagonais, híbridos, flutuantes. Criam-se outros traçados de conflitualidade, uma nova geometria da vizinhança ou do atrito. Talvez com isso a função da própria negatividade, na política e na cultura, precise ser revista. (PELBART, 2003, p. 142)

Quando ainda do mundo dividido em dois, a resistência era o embate frente a frente, as massas saíam às ruas para protestar, os sindicatos organizavam o proletariado contra a burguesia. Havia dois lados, havia pelo menos dois blocos ideológicos entre os quais escoIher. Porém, hoje, como fazer movimento de resistência às forças que nos impedem a vida? Essas forças foram injetadas nos homens de forma que já quase não se consegue imaginar a vida sem elas. A que recorrer para resistir? Como podemos reafirmar aquilo que é próprio do humano na sua possibilidade de criação de mundos, hoje, pós-indústria cultural, pós-biopoder, engenharia genética, psiquiatria química, Internet? Como descontinuar o controle?

É preciso criar um modo, uma ação que permita a existência, uma ação singular que possibilite a vida humana. Cada um, a cada captura, a cada tentativa de enquadramento no mundo pronto que nos obriga, poderia criar formas de existir humano. Re-existir. Podemos pensar a resistência hoje como insistência em criação. Insistir em existir continuamente: reexistir.

A partir do que vimos defendendo até então, podemos dizer que só nos restou o corpo; mesmo capturado, um corpo controlado, atravessado pelos controles a partir de dentro, com desejos programados, corpo que vive em um mundo dado que não Ihe permite viver, mas, ainda assim nos restou esse corpo: essa imagem que vejo no espelho, essa fonte de sensações e percepções. Se assim for, expor esse corpo poderia ser uma forma de resistência? Mostrar o poro, o avesso, as intimidades poderia ser uma forma de mostrar o que ainda pode escapar da captura, mesmo fugaz? Voltando ao universo específico desse artigo, perguntamos, seria o documentário em primeira pessoa um embate contra o não-ser? Podemos pensar o documentário em primeira pessoa como uma forma de resistência? Uma forma de reafirmar a existência, tentando escapar ao controle? Talvez a enunciação do eu mesmo seja a impossibilidade de assumir a 
voz do mundo dado pelo capitalismo. A impossibilidade de enunciar essa voz que não é sua, a impossibilidade de asserir sobre qualquer de suas verdades. Tomado sob esse prisma, não estaria o filme de um eu comum, que fala sobre si mesmo, amparado não por uma ética modesta na qual "[...] o sujeito que enuncia vai diminuindo o campo de abrangência de seu discurso sobre o mundo até restringi-lo a si mesmo. De si mesmo, o sujeito modesto ainda pode falar." (RAMOS, 2008, p. 38), mas por uma ética de resistência? Ao contrário de modéstia, uma empáfia de alguém que ousa opor-se ao mundo, que dá tudo o que tem, ele mesmo, insistindo na sua capacidade de criar?

Tomemos como exemplo de documentário em primeira pessoa, Tarnation (Maldição), de Johnatan Caouette, de 2004. É um filme que sem dúvida segue a narrativa do documentário e cujo tema é a vida do seu realizador. Neste filme ele conta sua história pessoal, desde a infância não nos poupando de detalhes íntimos que expõe sem pudor, escancarando suas complicadas relações familiares com hipótese de abusos, o fato de ser gay, o tratamento de choque para uma suposta doença psicótica da mãe. O filme mostra a criatividade de Couette, que soube reverter as limitações do uso de recursos caseiros na produção do filme em contribuições estéticas para o mesmo, assim como faz uma interessante montagem pouco linear que compõe com a citada esquizofrenia na família, mas não nos oferece nada que seja uma verdade com a qual possamos concordar ou da qual passemos a discordar.

Pode nos parecer que um filme assim é bem tímido em relação à tradição na qual encontramos asserções sobre o mundo, filmes que estão ali como bandeiras contra ou a favor de determinadas realidades, que se compõem em uma intenção de mudar o mundo. Porém, ao adotarmos a perspectiva que vimos colocando aqui, podemos dizer que filmes como este não estão preocupados em defender uma determinada posição ideológica teórica, mas sua ideologia é a de nos mostrar alguém que está vivo e que luta por expressar sua vida como bem entender. Cria um filme sobre si para mostrar que pode criar, que está vivo, que pode mostrar sua vida como quiser, pois essa lhe pertence. Já não pode mais asserir sobre o mundo porque the é negada a participação na criação do mundo, mas por meio de um filme pode criar e recriar a si mesmo, pode insistir na sua existência particular. $\mathrm{O}$ ato de criação é um ato de singularização. É o ato de alguém criando a sua versão.

Vamos pensar a produção de documentários em primeira pessoa para além da produção cinematográfica propriamente dita. Observamos hoje a avalanche tecnológica sob a qual vivemos, onde temos à disposição equipamentos cada vez mais versáteis, portáteis e baratos e, portanto, cada vez mais acessíveis a todas as camadas da população. As condições tecnológicas hoje permitem não a qualquer um, mas ao homem comum, falar sobre si mesmo para o mundo. A popularização do uso da Internet para praticamente tudo, desde a globalização da economia até o pedido de pizza da esquina é algo que nos atravessa de forma ultra-rápida e nos possibilita outras formas de relação com os outros, surgem novas possibilidades de realidades, de verdade e subjetivação. Por um olho podemos ver um maquinário estranho do qual o corpo já faz parte, uma malha intrincada sem começo nem fim cujos movimentos não podemos dominar, que nos aperta e comanda. Mas pelo outro olho podemos ver novos instrumentos de criação de sentido para a vida, um novo universo se abre cheio de possibilidades de criação de ser. Assim, paralelamente à revolução na produção de filminhos pessoais possibilitada pelos novos equipamentos eletrônicos, vivemos uma revolução também na distribuição dessas produções. O homem qualquer poder disponibilizar sua criação em redes de exposição e comunicação. Por meio de sites de relacionamento pode expor seus filmes a espectadores que selecione, em sites de postagem abertos pode dar acesso à sua produção ao mundo. Os filminhos de celular em sua maioria não são, como no exemplo de Tarnation, uma autobiografia completa, mas são documentários de fragmentos da vida de alguém, de momentos pessoais, vividos por um indivíduo que quer se mostrar aos outros. Não se trata aqui de discutir as qualidades técnicas dessas produções. Sua intenção não é fazer arte, a maioria desses filminhos que encontramos no youtube, por exemplo, talvez sejam feitos por pessoas que mal acabaram de sair da infância, pessoas que, por diversos motivos, não têm condições de discutir o estatuto da arte, sequer pensam nisso. O que importa é compartilhar a experiência de es- 
tar vivo. Quisemos aqui levantar e defender a hipótese de que a intenção da produção de documentários em primeira pessoa, característica dos tempos atuais, não é a de revelar uma verdade sobre o mundo a não ser a de que está vivo, reafirmando esta vida perante o mundo, mostrando a quem quiser ver até suas entranhas.

A invenção não é prerrogativa dos grandes gênios, nem monopólio da indústria ou da ciência, ela é a potência do homem comum (Tarde/Lazzarato). Todos e qualquer um inventam, na densidade social da cidade, na conversa, nos costumes, no lazer - novos desejos e novas crenças, novas associações e novas formas de cooperação. (PÉLBART, 2003, p. 138)

Michael Renov, em The Subject of Documentary, tem um capítulo no qual trata do que ele chama video confessions. Ele inicia com uma passada histórica sobre a cultura da confissão, citando os estudos de Foucault, inclusive, e depois passa a verificar os modos como os filmes que captam testemunhos pessoais, narrando também interessantes experiências de vídeo-instalações, podem funcionar como uma afirmação da psique de uma determinada subjetividade. Esta abordagem psicanalítica diverge da escolhida por nós aqui. No entanto, há, mesmo ainda dentro desta perspectiva de Renov, um aspecto que nos interessa vivamente, que é o de video-as-potentiality (vídeo como potencialidade), que ele apresenta ao comentar, entre outros, o trabalho The Love Tapes, de 1978. Trata-se de uma vídeo-instalação de Wendy Clarke (videomaker e psicanalista que faz experiências para investigar as potencialidades do vídeo-confissão para a psicanálise). Esta é a instalação de um pequeno Box contendo uma mesa com um monitor em cima, uma cadeira e uma câmera posicionada de modo a enquadrar em um meio close frontal a pessoa que se senta na cadeira. A proposta é a de dar a qualquer pessoa que queira a oportunidade de falar diretamente para a câmera sobre o que o amor significa para ela, podendo depois editar sua fala ou aceitá-la como está. Esse aparato é colocado em lugares públicos como na frente de um supermercado, em uma estação de ônibus, em uma prisão.

I remain convinced that it is video-as-potentiality that fuels the emotional impact of The Love
Tapes. What makes the experience of the tapes so powerful for subjects and audiences alike can never be duplicated on the couch. Clarke's success taps into the staggeringly hegemonic media current and temporarily redirects the flow. The very force that, while informing and entertening us, delivers us to the advertisers now becomes a vehicle for performig ourseves to ourselves. The professional analyst can elicit, mirror, and interpret the subject's desire but lacks the levering capacity that media apparatus inchoately mobilizes [...] In contrast to the legacy of photographic representation as one regulatory and disciplinary apparatus, first-person vídeo confessions of this sort afford a glimpse of a more utopian trajectory in which cultural prodution and consumption mingle and interact, and in which the media facilitate understanding across the gaps os human difference rather than simply capitalizing on those differences in a rush to spectacle. (RENOV, 2004, p. 208-215) ${ }^{1}$

Sobre o cinema direto de Jean Rouch, especificamente com Edgar Morin em Chronique d'un été, 1961, Renov também irá salientar o aspecto de nós para nós mesmos:

The camera is for Rouch a kind of two-way glass that retains a double function: it is a window that delivers the profilmic to an absent gaze and, at the same moment, a reflective surface that reintroduces us to ourselves. ${ }^{2}$ (RENOV, 2004, p.197)

Esse movimento de voltar a si mesmo do documentário em primeira pessoa, para Renov (2004, p.215), como para nós, "[...] permite vislumbrar uma trajetória mais utópica [...]". Para ele porque esse poderia facilitar

1 Livre tradução da autora: "Continuo convencido de que o vídeo-como-potencialidade serve de combustível para o impacto emocional de The Love Tapes. O que faz a experiência das filmagens ser tão forte para os sujeitos e a platéia não pode nunca ser duplicada no divã. O sucesso de Clarke tem relação direta com a corrente da mídia oscilantemente hegemônica e temporariamente redireciona o fluxo. A mesma força que, enquanto nos informa e nos entretém, nos leva à propaganda agora se transforma em um veículo para que possamos atuar como nós mesmos para nós mesmos. O analista profissional pode elucidar, espelhar e interpretar o desejo do sujeito, mas The falta a capacidade que o aparato midiático mobiliza. [...] Ao contrário do legado das representações fotográficas como aparatos regulatórios e disciplinares, os vídeos-confissão em primeira pessoa deste tipo permitem vislumbrar uma trajetória mais utópica na qual a produção cultural e o consumo se misturem e interajam, e na qual a mídia facilite o entendimento do outro ao invés de reforçar as diferenças humanas na pressa do espetáculo."

2 Livre tradução da autora: "Para Rouch a câmera é uma espécie de vidro [ou espelho] de duas faces que tem uma dupla função: é uma janela que leva o profilmic [a realidade fotografada frente à câmera, que no caso dos documentários direto/verdade deve ser preservada ao máximo] a um olhar ausente, e ao mesmo tempo é uma superfície reflexiva (que reflete no sentido de reflexo e não de reflexão) que nos re-apresenta a nós mesmos." 
o entendimento do outro, misturando o consumo à produção cultural, em contraposição ao reforço das diferenças como o faz a mídia. Para nós porque esse tipo de produção, ao se consumar como uma volta a si mesmo e necessariamente ao outro, já que é feita para ser exibida, muitas vezes em escala mundial, pode ser entendida como uma tentativa de afirmação da existência desse sujeito cuja vida não cessa de ser capturada pelos aparatos do capitalismo. Sendo assim, a potencialidade política desse tipo de produção é de resistência. Talvez possamos afirmar que, de alguma forma, trata-se de uma subversão da força da mídia. Esta força que "[...] nos informa, nos entretém e nos leva à propaganda [...]" (RENOV, 2004, p.208), é subvertida e "[...] agora se transforma em um veículo para que possamos atuar como nós mesmos para nós mesmos [...]" (RENOV, 2004, p.208), não no sentido psicanalítico, mas político. Assim, para finalizar, citamos o professor brasileiro da Faculdade de Comunicação da Universidade Federal da Bahia, André Lemos:

Talvez estejamos vendo emergir, pela primeira vez, funções verdadeiramente comunicacionais e dialógicas dos produtos fotográficos e videográficos. Esses produtos passam a funcionar efetivamente como mídia de comunicação, já que me coloca em contato com outro, já que permite diretamente a troca entre consciências, e não a função de fruição estética em uma galeria ou na sala escura do cinema. Mais do que exposição busca-se o que é vivido junto, a cumplicidade. Não mais sociedade do espetáculo, mas o espetáculo da vida banal do dia-a-dia compartilhando. [...] as tecnologias de comunicação móvel tornam-se artefatos de função pós-massiva, de transformação da representação de si e da ligação espaço-temporal ao espaço urbano e ao outro na atual cibercultura [...] Não se trata apenas de se 'informar' (pelas funções massivas dos meios), mas de produzir, conectar e reconfigurar a cultura e as formas de sociabilidade pelas novas funções pós-massivas emergentes [...]" (LEMOS, 2007, p. 11-12)

Queremos mais uma vez enfatizar que a atual possibilidade de produção e circulação individualizadas de comunicação e novas formas de sociabilização permitidas hoje pela tecnologia disponível, grifadas pelo professor citado, é quase sempre usada para exibir um conteúdo pessoal, revelando a necessidade de falar de si. Esse falar de si mesmo, hoje, pode funcionar como uma resistência política contra todo o aparelho de Estado montado e super equipado que o tempo todo nos fala de cada um de nós, para que saibamos sobre nós mesmos através dele. Pensamos que podemos operar esse mesmo aparato que nos obriga à exposição para o controle, subvertendo-o e usando-o para falarmos de nós mesmos para nós mesmos na tentativa de criarmos autonomamente nossas vidas.

\section{Referências}

AGAMBEN, G. Homo Sacer: o poder soberano e a vida nua I. Belo Horizonte: Ed. UFMG, 2004.

DELEUZE, G. Controle e Devir: entrevista a Toni Negri. In: Conversações: 1972-1990. Rio de Janeiro, 1992a. P. 209-218.

DELEUZE, G. Post-scriptum sobre as sociedades de controle. In: Conversações: 1972-1990. Rio de Janeiro, 1992b. P. 219-226.

FOUCAULT, M. História da Sexualidade I: a vontade de saber. 3. ed. Rio de Janeiro: Ed. Graal, 1980.

LAZZARATO, M. As Revoluções do Capitalismo. Rio de Janeiro: Civilização Brasileira, 2006.

LEMOS, A. Comunicação e Prática Sociais no Espaço Urbano: as características dos Dispositivos Híbridos Móveis de Conexão Multirredes (DHMCM). [2007]. (No prelo) Disponível em: <http://www.facom.ufba.br/ciberpesquisa/andrelemos/ DHMCM.pdf> Acesso em: 29 de setembro de 2009 
NICHOLS, B. Blurred Boundaires: Questions of Meaning in Contemporary Culture. Bloomington: Indiana University Press, 1994.

PELBART, P.P. Vida Capital: ensaios de biopolítica. São Paulo: lluminuras, 2003.

RAMOS, F.P. Mas Afinal... o que é mesmo documentário? São Paulo: Ed. Senac, 2008.

RENOV, M. The Subject of Documentary. Minneapolis: University of Minnesota Press, 2004.

Recebido em outubro de 2009.

Aprovado para publicação em março de 2010.

\section{Renata Lima Aspis}

Graduada em Filosofia, Mestre em Filosofia da Educação pela UNICAMP, doutoranda em Filosofia da Educação pela UNICAMP - São Paulo-SP/Brasil - no grupo DiS, Diferenças e Subjetividades em Educação. Bolsa doutorado FAPESP. Professora de Filosofia para Ensino Médio.

Email: renaspis@terra.com.br. 